\title{
Umbilical hernia repair with composite prosthesis: Author's reply
}

\author{
J. L. Porrero ${ }^{1} \cdot$ O. Cano-Valderrama $^{2}$
}

Received: 13 May 2019 / Accepted: 18 May 2019 / Published online: 27 May 2019

(c) Springer-Verlag France SAS, part of Springer Nature 2019

We have read with interest the comment to our paper "Umbilical hernia repair with composite prosthesis: a singlecentre experience" [1] by Kulacoglu [2].

As Kulacoglu says, composite prostheses are more expensive than polypropylene mesh, and using them in the preperitoneal space is doubtful. Nevertheless, surgery is easier with these prostheses, as the memory ring contributes to mesh deployment. It would be interesting to perform a study comparing composite mesh vs. polypropylene mesh in the preperitoneal space. Preperitoneal dissection could be smaller when a composite mesh is used, and this could decrease the incidence of surgical site occurrences. Complications could also be avoided when peritoneal inadvertent opening occurs. Moreover, recurrence rate should be studied; because our recurrence incidence (3.9\% with a follow-up longer than 4 years) was quite satisfactory.

Several financial points must also be noted. First, as surgery is easier when using the composite prosthesis, the procedure could be faster. If the procedure is fast enough to allow one more patient operated during the surgical session, the financial gap will decrease. Second, when the composite mesh is purchased for all the procedures, the prize per unit is lower. Finally, composite prosthesis repair should not be compared only to polypropylene mesh repair, as many other procedures are currently being used for umbilical hernia surgery. Procedures such as robotic and laparoscopic umbilical hernia repair should also be economically compared to composite prosthesis repair. Probably composite prosthesis repair is more cost-efficient than all these procedures.

This reply refers to the comment available at https://doi. org/10.1007/s10029-019-01980-2.

O. Cano-Valderrama

oscarcanovalderrama@hotmail.com

1 Department of Surgery, Hospital Universitario Santa Cristina, Madrid, Spain

2 Department of Surgery, Hospital Universitario Clínico San Carlos, C/ Profesor Martin Lagos SN, 28040 Madrid, Spain
The comment by Kulacoglu also inquired about the effect of anesthesia in recurrence. Analyzing our series recurrence incidence was $5.3 \%, 3.8 \%$ and $3.8 \%$ after general, local and regional anesthesia $(p=0.665)$.

Finally, the question about the relationship between obesity and recurrence with a cutoff set at $35 \mathrm{~kg} / \mathrm{m}^{2}$ cannot be answered, as obesity was codified as a binary variable.

\section{Compliance with ethical standards}

Conflict of interest J. L. Porrero and O. Cano-Valderrama declare that they have no conflict of interest.

Ethical approval This study was reviewed and approved by the Intitutional Review Board.

Human and animal rights All procedures performed in studies involving human participants were in accordance with the ethical standards of the institutional and/or national research committee and with the 1964 Helsinki declaration and its later amendments or comparable ethical standards.

Informed consent For this type of study, formal consent was not necessary.

\section{Reference}

1. Porrero JL, Cano-Valderrama O, Villar S, Sánchez-Cabezudo C, Ramos B, Porrero B, Cendrero M, Bonachia O, Torres AJ (2019) Umbilical hernia repair with composite prosthesis: a single-centre experience. Hernia 23(1):143-147

2. Kulacoglu H (2019) Comment to: Umbilical hernia repair with composite prosthesis: a single-centre experience. Hernia 23:143147 (In press in this issue. Epub ahead of print)

Publisher's Note Springer Nature remains neutral with regard to jurisdictional claims in published maps and institutional affiliations. 